\title{
“Fuzzy-Needs” Based Competitive Sets: Structure and Use
}

\author{
Sandra J. Burke, Macquarie Graduate School of Management
}

\begin{abstract}
A framework to aid in identifying relevant competitive sets in dynamic markets is proposed. It utilizes goal-oriented consumer categorization to derive competitive sets defined by consumers' fuzzy needs-based consideration sets. Competitive sets are thus usage occasion specific, have fuzzy structures based on degree of multiple needs fulfilment, and change over time. This view differs from traditional competitive identification as the degree of competition is based on how similarly competitors are viewed as fulfilling the same multiplicity of needs and are in the same consideration sets across differing need fulfilment occasions. The framework suggests how and when competitive sets should be identified and monitored to assess structural changes.
\end{abstract}

\section{Introduction}

Competitive identification and analyses are integral parts of strategic marketing. To identify an appropriate competitive position, organisations must recognize competitors' skills and capabilities to determine opportunities for sustainable advantage (Porter, 2001). While many organisations assume competitive sets are given, determining which competitors should be considered in strategic analysis is a key first step. Competition is a matter of degree, not a yes or no question (Day, Shocker and Srivastava, 1979; Kotler, 2004), and where an organisation draws the boundaries on who to analyse can play a critical role in their success. If key competitors are left out of analyses, it could lead to poor planning. However, if boundaries are too broad, analytical tasks can be cumbersome and less relevant (Porac and Thomas, 1990). Without clear, accepted competitive sets, even simple KPI's such as market share can be arbitrary and misleading.

Accurate and diagnostic competitive definition is becoming more difficult in many industries (Hamil and Valikangas, 2003). Dynamics are making industry lines more fragmented, vague, and shifting on a more frequent basis. To do competitive analyses that properly informs competitive positioning, managers must take a more specific yet fluid view of with whom they are competing in general (Peteraf and Bergen, 2003) and on particular usage occasions. This paper proposes a framework to aid in understanding the graded and shifting nature of needs-based competitive sets. The framework uses consumer categorization to suggest how and when competitive sets should be monitored to understand changes in structures over time and usage occasions. The framework differs from traditional competitive identification in that competition is a function of the similarity of multiple needs fulfilment and how often consumers view brands in the same consideration sets across differing occasions.

\section{Conceptual Development}

From the supply-based (product-market) perspective, competition is defined by categorising organisations into "strategic groups" consisting of those that share similar attributes, resources 
and capabilities, and produce similar types of products (Peteraf and Bergen, 2003; Porac and Thomas, 1990). However, such approaches fail to consider that competition occurs in the minds of consumers (DeSarbo, Grewel and Wind, 2006). In a purchase decision, if a consumer is choosing between one product and another, the firms are competitors regardless of how similar they are from a resource-based perspective. From market-based perspectives firms are considered competitors if, from the consumers' point-of-view, the y can be substituted to fulfil the same benefits and needs (Peteraf and Bergen, 2003; Porac and Thomas, 1990).

A considerable amount of research examines how consumers categorize products into cognitive product categories. However, such research does not necessarily identify how consumers derive consideration sets on any particular usage/purchase occasion. Research suggests consumers hold beliefs about sets of attributes that define and are common to a category and products are categorized according to how many attributes they share with category "prototypes" (Mervis and Rosch, 1981). Thus, cognitive product categories consist of products, brands, or offers that are perceived similar to one-another and different to those outside the category. Research also suggests product categories have graded structures. Viswanathan and Childers (1999) conceptualize this structure as one of fuzzy sets wherein products vary in their degree of membership based on their ratings on key continuous attributes. Yi and Gray (1996) introduce attribute diagnosticity, the degree to which an attribute is common within a category and distinctive across categories, as a determinant of perceived typicality of products relative to a category. They show that when a product possesses a highly diagnostic attribute, it's seen as more typical of a target category and less typical of a nontarget category. Finally, research suggests cognitive product categories are hierarchical in nature in that products may be categorized at several levels with higher levels being more abstract and thus inclusive of lower levels (Burke, Milberg and Moe, 1997; Mervis and Rosch,1981; Sujan and Bettman, 1989).

While research provides insight into how products are categorized into memory, to identify an actionable competitive set o rganisations must determine which competitors consumers consider and choose amongst at the time of purchase. Recent research recognizes that prior to making a purchase, consumers recall sets of products to fulfil specific usage occasion goals and choose from that consideration set (Cowley and Mitchell, 2003; Desai and Hoyer, 2000; Huffman and Houston, 1993). Membership in consideration sets is relative to the specific goals the consumer is trying to fulfil at that usage occasion. It is suggested that consumers seek features and attributes to fulfil specific goals based on feature-to-goal associations stored in memory that indicate the relevance of the feature to fulfilling the goal (Huffman and Houston, 1993). They also use brand-to-feature and brand-to-goal associations to access and select members for specific usage occasion consideration sets. Thus, a product categorized in one cognitive product category may be accessed to form goal-derived consideration sets that consist of very different members to answer specific usage requirements. For example, Starbuck's might be categorized into memory as a coffee shop. However, Starbuck's may be accessed in a number of different goal-derived consideration sets that answer different need questions such as "where to go to do some work away from the office." Importantly, this goal-derived consideration set would not likely include some other "coffee shop" product category members such as McDonalds or a takeaway coffee outlet, yet would include noncoffee shop members such as the park or the library.

While research shows goal-derived consideration sets differ from cognitive product categories, how to use that information to identify competitive sets for strategic analyses 
remains unclear. Research has begun to investigate how to identify competition from the needs-based consideration set perspective (Christensen, Cook and Hall, 2005; DeSarbo, Grewel and Wind, 2006; Peteraf and Bergen, 2003). Multidimensional scaling and conjoint techniques have long been used to methodologically derive market segments and corresponding competitive sets based on consumers' perspectives of brands' strengths, weaknesses and similarities (Johnson, 1971; Green and DeSarbo, 1979). More recently, DeSarbo, Grewel and Wind (2006) present a stochastic MDS procedure that uses consumer consideration sets to determine competitive asymmetries. However, MDS methods are often descriptive and don'tidentify drivers of the consideration set classification but instead identify how much of unidimensional attributes brands possess. They do not define consideration sets from a needs fulfilment perspective and changes in sets across time or usage occasions cannot be anticipated, limiting their use in predicting future choice sets for strategic marketing purposes. Peteraf and Bergen (2003) agree that firms compete to the extent they attract the same customers and fulfil the same customer needs. They suggest similarities in resource functionality in terms of fulfilling needs ultimately determine rivals. This research provides guidance in assessing resource functionality as a driver of competitive sets. However, no framework is available to help managers identify their most direct competitors from a needs-based perspective.

\section{Fuzzy Needs-Based Competitive Sets}

This paper proposes such a framework to aid managers in identifying competitive sets from a "fuzzy needs" consideration set perspective. It suggests that needs-based consideration sets may be somewhat different from cognitive product or goal-derived categorizations suggested in previous research. Contrary to product categories, goal and needs-based categories may include members from several product categories and are used for instantiation rather than classification (Barsalou, 1985). Thus, they may not maximize the correlational structure of typical product categories, stand out as natural groups, or be salient or relevant other than when retrieved for instantiation of ways to fulfil pursued needs. Needs-based considerations sets may also differ in terms of the factors that drive their graded structure (Barsalou, 1985). Attribute diagnosticity drives the degree of product category membership (Mervis and Rosch 1981, Yi and Gray, 1996) and strength of the link between brand, features, and goal or benefit fulfilment drives the likelihood of membership in goal-derived consideration sets (Desai and Hoyer, 2000; Huffman and Houston, 1993). However, "total needs fulfilment diagnosticity," the degree of functionality of attribute sets in terms of fulfilling the multiplicity of needs on a given occasion, may determine likelihood of membership in usage occasion needs-based consideration sets. Many specific usage occasions are associated with complex sets of needs. The degree to which alternative brands or products fulfil the full array of needs may drive the graded structure of needs-based competitive sets. For example, the needs that a consumer may try to fulfil with the purchase of a BMW might include status, adrenalin rush, and transportation. Competitors that fulfil all of the same needs will most often be included in consideration sets with BMW over time and varying usage occasions. Thus, they can be seen as BMW's most direct competitors. Those offers that fulfil some of the same needs may sometimes be included in the same consideration sets with BMW and are more indirect competitors. Thus, the degree to which firms similarly fulfil the total need structure determines the degree of direct competitiveness and the "fuzzy-needs" based competitive set.

This perspective of "fuzzy-needs" graded structures also suggests that these competitive sets are not clearly hierarchical. For example, BMW's less direct competitors would be those offers that fulfil more fragmented, separate needs such as adrenalin rush OR status. Those 
sets are separate and might include very different members from one another such as skydiving (adrenalin) and Rolex watches (status). Thus, lower levels are not clearly subsumed by singular higher levels of consideration sets. The proposed "fuzzy-needs" competitive set structure is depicted in Figure 1.

Research Proposition 1: Competitive sets are defined byconsumers' fuzzyneeds-based consideration sets that are specific to a usage occasion, have a fuzzy structure based on degree of multiple needs fulfilment, and are not necessarily hierarchical.

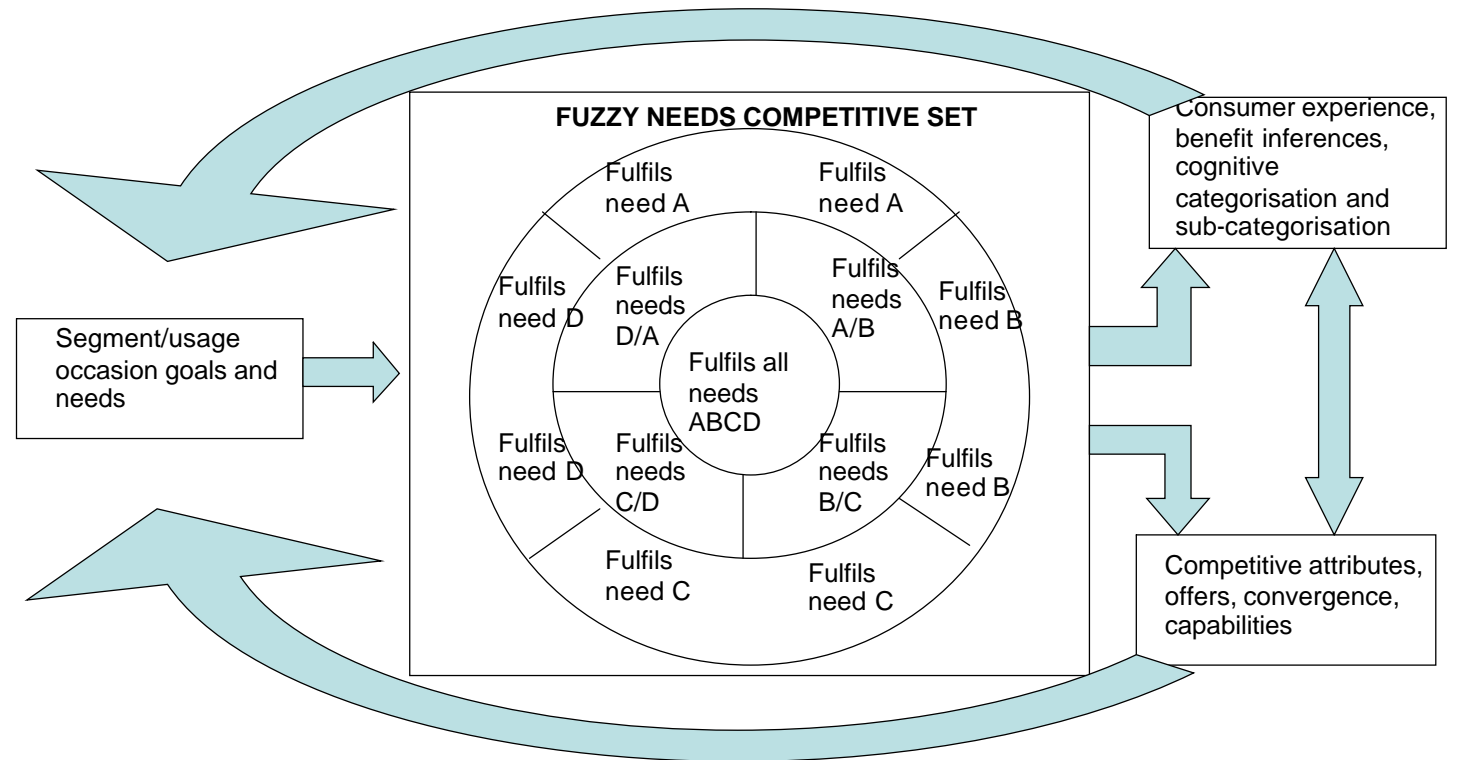

Figure 1: Fuzzy Needs-Based Consideration Set Structure and Evolution

\section{Dynamic Consideration Sets}

Competitive sets aren't static and analyses cannot treat them as such. Industries vary in terms the pace at which competitive sets shift and how often competitive definition must be monitored. Research has only begun to investigate the dynamic nature of competitive sets. Srinivasan, Lilien, and Rangaswamy (2006) suggest that competitive sets change as dominant designs emerge. Before the emergence of the dominant design, competition is between designs. After a design achieves dominance, competition is between players within the dominant design domain. A number of studies have shown that marketers influence change in consideration sets. By emphasizing attributes that are common to a subcategory but different from a broader product category marketers can alter consumers' perceived category structure (Broniarczyk and Gershoff, 2003; Burke, Milberg and Moe, 1997). Other research suggests that product categories are essentially socially constructed knowledge structures shared amongst producers and consumers (Rosa, Porac, Runser-Spanjol and Saxon, 1999). Thus, they go through phases of instability and stabilization as shared knowledge structures change due to social interactions and activities of market actors.

This paper suggests that fuzzy needs-based consideration sets evolve and must be monitored regularly to maintain a clear understanding of competitive sets. Research suggests that ad hoc goal-derived categories are initially formed to achieve novel goals but become more stable categories in memory with frequent use (Barsalou, 1985). Similarly, needs-based consideration sets are likely to stabilize as the same needs are addressed with frequency 
(Desai and Hoyer, 2000). However, a number of factors may drive fluctuations and variation in those consideration sets. First, as described above, fuzzy needs-based consideration set membership is a function of the degree to which the complex needs of the usage occasion are met. As the usage occasion defines the associated complex needs, moving across usage occasions will result in different need sets and corresponding competitive sets to fulfil those needs. Further, consumer needs change as they gain experience in various usage occasions and their knowledge of the specific needs they strive to fulfil becomes better defined (Cowley and Mitchell 2003). Finally, competitive offers change over time in terms of how attributes and features are delivered to fulfil various needs. Importantly, the fluid nature of competitive sets means competition must be assessed based on which firms most commonly accompany one another in consideration sets across segments, usage occasions and time and must be redefined as needed to stay relevant.

Research Proposition 2: Competitive sets derived from fuzzy needs are dynamic and vary across usage occasions and over time as competitive activities shift and consumer knowledge evolves.

\section{Conclusion, Managerial Implications and Future Research}

Identifying accurate and diagnostic competitive sets is a critical step in strategic marketing/positioning. This task is becoming more challenging in the changing, hypercompetitive, complex environments of many modern industries. Yet, few tools are available to aid managers in this onerous task. The proposed framework fills that gap by providing a tool designed to aid managers in identifying relevant competitive sets in dynamic markets. The "fuzzy-needs" based graded structure and dynamic nature of the sets proposed in the framework have significant implications for strategic analyses. Toidentify relevant competitive sets, managers must access consideration set information from consumers across a number of segments and usage occasions. Those competitors most frequently and consistently included in common consideration sets are the organisation's most direct competitors. However, the graded structure of the competitive set also identifies which and why more indirect competitors are relevant to varying degrees in specific usage occasions. Finally, managers must monitor and redefine competitive sets over time to track changes such as sub-categorisation, shifting needs and consumer experience, and changing competitive offers. Shifts in the competitive structure and changes in the degree of direct competitiveness among players are also more accurately predicted by understanding the "why" underlying the competitive set structure.

The effectiveness of the proposed framework must be empirically tested to determine whether the competitive sets derived are in fact more accurate and diagnostic than those of other competitive set models. To that end, next steps include designation of an experiment that compares competitive sets elicited using the various models such as market mapping (MDS) and fuzzy set cognitive product categorizations. The similarities, differences and diagnosticity of the sets in terms of reflecting consumer consideration sets across segments, usage occasions, and time will be evaluated. 


\section{References}

Barsalou, Lawrence 1985. "Ideals, Central Tendency, and Frequency of Instantiation as Determinants of Graded Structure in Categories," Journal of Experimental Psychology: Learning, Memory, and Cognition, Oct. Vol 11(4)

Broniarczyk, Susan M. and Andrew D. Gershoff 2003. "The Reciprocal Effects of Brand Equity and Trivial Attributes," Journal of Marketing Research, May Vol XL 161-175.

Brown, Christine 1996. "It's News to Me: Framing Effects in New Categories and New Situations," Advances in Consumer Research, Vol 23.

Burke, Sandra J., Sandra J. Milberg and Wendy W. Moe 1997. "Displaying Common but Previously Neglected Health Claims on Product Labels: Understanding Competitive Advantages, Deception, and Education," Journal of Public Policy and Marketing, Fall, Vol 16.

Christensen, Clayton M., Scott Cook and Taddy Hall 2005. "Marketing Malpractice," Harvard Business Review, Dec.

Cowley, Elizabeth and Andrew A. Mitchell 2003. "The Moderating Effect of Product Knowledge on the Learning and Organization of Product Information," Journal of Consumer Research, Dec. Vol 30

Day, George, Allan D. Shocker and Rajendra K. Srivastava 1979. "Customer-Oriented Approaches to Identifying Product-Markets," Journal of Marketing, Fall.

Desai, Kalpesh Kaushik and Wayne D. Hoyer 2000. "Descriptive Characteristics of MemoryBased Consideration Sets: Influence of Usage Occasion Frequency and Usage Location," Journal of consumer Research, Dec. Vol 27

DeSarbo, Wayne S., Rajdeep Grewal and Jerry Wind 2006. "Who Competes With Whom? A Demand-Based Perspective for Identifying and Representing Asymmetric Competition," Strategic Management Journal 27; 101-129.

Green, Paul and Wayne DeSarbo 1979. "Componential Segmentation in the Analysis of Consumer Trade-Offs," Journal of Marketing, Fall, Vol. 43

Hamil, Gary and Liisa Valikangas 2003.“The Quest for Resilience,” Harvard Business Review, Sept. 52-63.

Huffman, Cynthia and Micahel J. Houston 1993. "Goal-oriented Experiences and the Development of Knowledge," Journal of Consumer Research, Sept. Vol 20

Johnson, Richard 1971. "Market Segmentation: A Strategic Management Tool," Journal of Market Research, Feb. Vol VII.

Kotler, Phillip 2004. Marketing Management, Pearson Prentice Hall , New Jersey 
Mervis, C. and E. Rosch 1981. "Categorization of Natural Objects," Annual Review of Psychology, 32, 89-115

Peteraf, Margaret A. and Mark Bergen 2003. "Scanning Dynamic Competitive Landscapes: A Market-Based and Resource-Based Framework," Strategic Management Journal, 24; 10271041 .

Porac, Joseph F. and Howard Thomas 1990. "Taxonomic Mental Models in Competitor Definition," Academy of Management Review, Vol 15, 224-240.

Porter, Michael 2001. "Strategy and the Internet,” Harvard Business Review, Mar.63-79.

Rosa, Jose Antonio, Joseph Porac, Jelena Runser-Spanjol, and Michael Saxon 1999.

"Sociocognitive Dynamics in a Product Market," Journal of Marketing, Vol 63, Special Issue 54-77.

Srinivasan, Raji, Gary Lilien and Arvind Rangaswamy 2006. "The Emergence of Dominant Designs," Journal of Marketing, April, Vol. 7.

Sujan, Mita and James R. Bettman 1989. "The Effects of Brand Positioning Strategies on Consumers' Brand and Category Perceptions: Some Insight from Schema Research,” Journal of Marketing Research, Nov. Vol 26

Viswanathan, Madhubalan, and Terry L. Childers 1999. "Understanding How Product Attributes Influence Product Categorization: Development and Validation of Fuzzy Set-Based Measures of Gradedness in Product Categories," Journal of Marketing Research, Feb. Vol 36 75-94.

Yi, Youjae and Kenneth C. Gray 1996. "Revisiting Attribute Diagnosticity in the Context of Product Typicality,” Psychology \& Marketing, Sept. Vol 13(6) 605-632. 


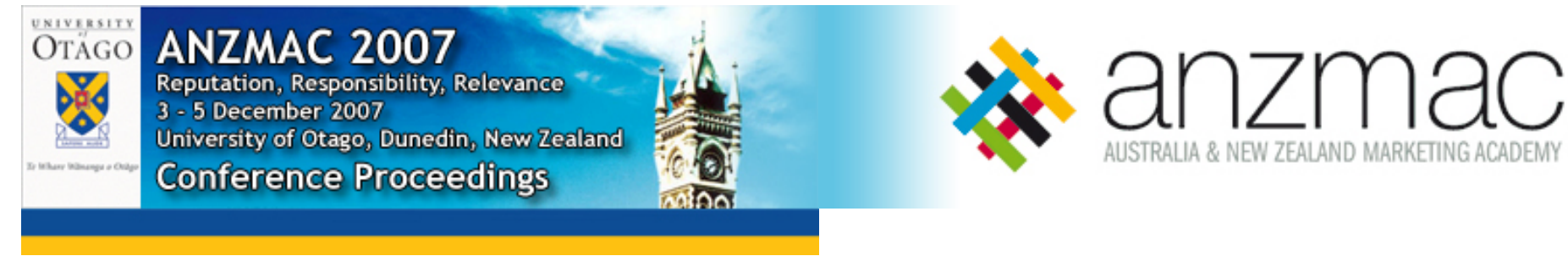

\section{Home}

Welcome from the Anzmac President

Welcome from the Conference Chair

Keynote Speaker

Conference Papers

ANZMAC Conference

Committee

Special Sessions

\section{Welcome to the Australian and New Zealand Marketing Academy (ANZMAC) Conference 2007}

Hosted by:

Date:

Venue:

Conference Chair:

Conference Proceedings Chair:

Conference Editors:

ISBN for Program and Abstracts

ISBN for Proceedings CD
Department of Marketing, School of Business, University of Otago

3-5 December 2007 (Monday - Wednesday) University of Otago, Dunedin, New Zealand

Dr. Kenneth R. Deans.

Dr Maree Thyne

Dr Maree Thyne

Dr Kenneth R. Deans

Associate Professor J uergen Gnoth

978-1-877156-28-0

978-1-877156-29-9
The ANZMAC 2007 theme 3Rs - Reputation, Responsibility \& Relevance seeks to bring to the fore a lively discussion on a number of issues and challenges facing our discipline. These challenges and issues were highlighted in a recent collection of essays published in the October $2005 \mathrm{~J}$ ournal of Marketing. The issues brought to light include:

- Marketing's status and relevance within the modern organisation;

- More boundary spanning in research and practice, and taking advantage of crossfunctional opportunities;

- More emphasis on strategy implementation;

- Broadening vision and goals;

- Ethics and social responsibility;

- Encouraging research that is relevant to society; and

- Researching markets outside the USA, UK and Europe.

In short, through addressing these issues, the Marketing discipline will maintain its reputation, responsibility and relevance. Through the conference we hope that delegates have developed valuable insights, a deeper understanding and a sense of how to advance our discipline. 


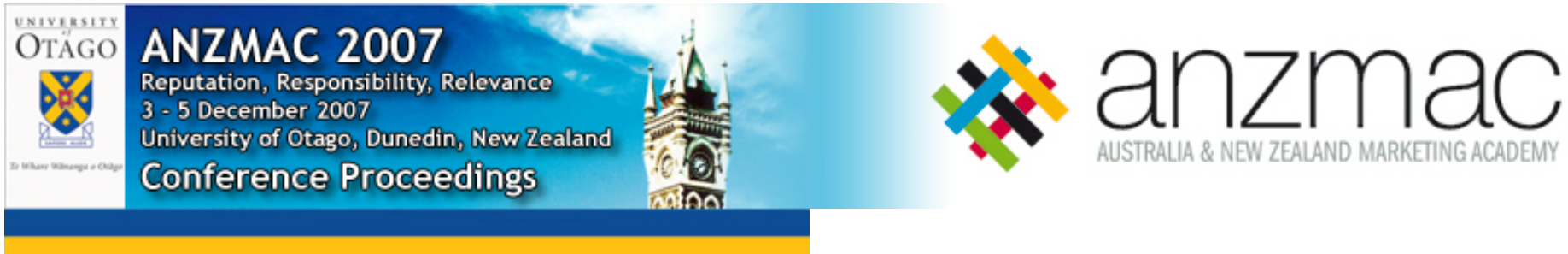

Home

Welcome from the Anzmac

\section{Conference Paper List by Author}

President

Welcome from the Conference

$A|B| C|D| E|F| G|H| I|J| K|L| M|N| O|P| Q|R| S|T| U|V| W|X| Y \mid Z$

Chair

Keynote Speaker

A

Conference Papers

Papers by Author

Papers by Track

ANZMAC Conference

Committee

Special Sessions

Top

Adam, Stewart Online Marketing by Local Government in Australia and the United States

Adamsen, J annie MiaAn Agenda to Construct an Improved Understanding of Australian Organic Consumers

Kristen Lyons, Hume Winzar, Sharyn Rundle-Thiele

Ainsworth, J eremy Consumer Comfort: A Retail Perspective

J amye Foster

Albarq, Abbas Antecedents of Consumer Ethnocentrism

Nik Kamariah Mat

Albert, Noel The Feeling of Love Towards Brands: the French Touch

Dwight Merunka, Pierre Valette-Florence

Ali, Shameem Profiling Operators of Commercial Homes: Gender Differences

Susan Zeidan

Andrésen, Edith Networking in Engineered and Emergent Processes

Heléne Lundberg

Andrews, Lynda Extending Holt's (1995) Typology of Consumption to Examine the Marketing Domain in the Experiential Consumption of Mobile Phones Judy Drennan

Ang, Lawrence Changing Brand Personality through Celebrity Endorsement Chris Dubelaar, Wagner Kamakura

Arambewela, Rodney Differences in Study Approaches and the Implications for Student Learning

Pam Mulready, Bill Callaghan

Archer, Catherine Corporate Social Responsibility, Descriptive Stakeholder Theory and Global Warming: A Case Study of Exxon-Mobil's Changing Views on 
Ann-Marie Kennedy

Budiman, Arief

Butt, Irfan

Burford, Marion

Burke, Paul

Burke, Paul

Burke, Sandra

Burrell, Amanda

Burrell, Amanda

Burrell, Amanda
Studying the Effects of Materialism, Religiosity and Status Consumption on Subjective Well-Being: An Indonesian Perspective Aron O'Cass

Development of Positioning as a Research Stream: A Critical Assessment of Impediments and a Look Forward Nicolas Papadopoulos, Steven Murphy

Learning from Student's Individual Commentaries

Museum Visitors Care about Everything! Using Best-Worst Scaling for Strategic Focus

Christine Burton, Chelsea Wise, J ordan Louviere, Twan Huybers

The Young and the Reckless: Message (In)Effectiveness about the Physical Consequences of Motor-Vehicle Accidents for Young Inexperienced Drivers

Luke Greenacre

"Fuzzy-Needs" Based Competitive Sets: Structure and Use

Be Quiet and Stand Still! It's good advice for marketing lecturers Michael Coe

Less Means More When it Comes to Fear Appeals and Teenage Drivers Tonia Gray, Brendan Gray

Making an Entrance: The First Two Minutes Can Make or Break A Lecture Shaun Cheah

Bustos, Anne-Maree Readiness for Competitive Positioning: A Managerial Checklist Sandra Burke

Buttriss, Gary $\quad$ Organisational Sustainability: Local Response to Global Issues

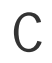

Top

Cadeaux, Jack Retail Assortment Variation and Sales: A Cross-Category Analysis LayPeng Tan

Callahan, Susan The Illusive Matter of Terroir: Can it be duplicated in the New World?

Carlson, J amie An Investigation of B2C Internet Commerce: E-Service Quality's Impact on Satisfaction, Attitudes and Behaviours

Aron O'Cass 